\title{
Effect of an Inhibitor of Neuronal Nitric Oxide Synthase 7-Nitroindazole on Cerebral Hemodynamic Response and Brain Excitability in Urethane-Anesthetized Rats
}

\author{
C. BROŽÍČKOVÁ ${ }^{1}$, J. OTÁHAL $^{1}$ \\ ${ }^{1}$ Department of Developmental Epileptology, Institute of Physiology, Academy of Sciences \\ of the Czech Republic, Prague, Czech Republic
}

Received March 14, 2013

Accepted May 7, 2013

\section{Summary}

The role of neuronal nitric oxide synthase (nNOS) in the pathophysiology of epilepsy and seizures remains disputable. One of the reasons why results from the acute in vivo studies display controversies might be the effect on the regulation of cerebral blood flow (CBF) during pharmacologically induced alterations of NO system. We examined neurovascular coupling in the rat sensorimotor cortex in response to transcallosal stimulation under nNOS inhibition by 7-nitroindazole (7-NI). Adult Wistar rats were anesthetized with urethane and epidural silver EEG electrodes were implanted over sensorimotor cortices. Regional CBF was measured by Laser Doppler Flowmetry (LDF). We catheterized a common carotid artery to measure arterial blood pressure (BP). 7-NI did not significantly affect blood pressure and heart rate. Electrophysiological recordings of evoked potentials (EPs) revealed no effect on their amplitude, rhythmic potentiation or depression of EPs. Transcallosal stimulation of the contralateral cortex induced a frequency dependent rise in CBF. Although 7-NI did not significantly affect basal CBF and cortical excitability, hemodynamic responses to the transcallosal stimulation were diminished implicating a role of nNOS in neurovascular coupling. Urethane anesthesia is suitable for future epileptological experiments. Our findings demonstrate that NO contributes to the hemodynamic response during brain activation.

\section{Key words}

Cerebral hemodynamic response • Brain excitability • Neuronal nitric oxide synthase $\bullet$ 7-nitroindazole $\bullet$ Rat

\section{Corresponding author}

Jakub Otáhal, Institute of Physiology, Academy of Sciences of the Czech Republic, Vídeňská 1083, 14220 Prague 4, Czech
Republic. Fax: +420-241062488.

E-mail: jotahal@epilepsy.biomed.cas.cz

\section{Introduction}

Nitric oxide (NO) is synthesized by a family of enzymes nitric oxide synthases (NOS) present in most of the cells of the body. There are four members of the NOS family: neuronal NOS (nNOS), endothelial NOS (eNOS), inducible NOS (iNOS) and mitochondrial NOS (mtNOS). The last one mentioned is an isoform of nNOS present in the inner mitochondrial membrane. All the isoforms share between 50 and $60 \%$ sequence homology. The nNOS and eNOS are $\mathrm{Ca}^{2+}$-calmodulin-dependent enzymes constitutively expressed in mammalian cells that generate an increase of NO lasting a few minutes. In contrast, iNOS is $\mathrm{Ca}^{2+}$-calmodulin-independent and its regulation depends on de novo synthesis. iNOS is expressed following immunological or inflammatory stimulation in macrophages, astrocytes, microglia and other cells producing high amounts of NO lasting hours or days (Buchholzer and Klein 2002, Guix et al. 2005). LArginine is used as a substrate by NOS to produce NO and citrulline in a process requiring NADPH and $\mathrm{O}_{2}$.

The ubiquitous localization of $\mathrm{NO}$ indicates its implication in a wide range of physiological processes, but it can also produce harmful effects due to its reactivity, mainly with proteins, under various pathophysiological conditions. A multitude of regulatory processes have been attributed to the nitric oxide since its first recognition as a signaling molecule in the central nervous system. NO is involved in the regulation of 
synaptic transmission and plasticity (Bon and Garthwaite 2003, Garthwaite et al. 1988), blood flow (Lindauer et al. 1999a), mitochondrial respiration (Brown 2001), as well as in inflammatory processes (Bal-Price and Brown 2001). NO as neuromodulator interferes with glutamate, GABA, monoamine, adenosine and cholinergic neurotransmission (Buchholzer and Klein 2002, Prast et al. 1998, Saransaari and Oja 2004, Trabace et al. 2004, Wall 2003). The importance of NO in the brain is determined by its broad effects on neuronal, glial and vascular compartments and its involvement in neurodegenerative diseases (Guix et al. 2005).

The main NO cellular signaling pathway is through the activation of guanylate cyclase (GC) with the subsequent production of cyclic guanosine-3', 5'monophosphate (cGMP) and protein phosphorylation (Guix et al. 2005). The mechanisms linking the rise in cyclic GMP content to the various effects of NO in the CNS are not fully understood, although it seems that the final step is a reduction of cytosolic calcium. Another action of NO independent of soluble guanylate cyclase (sGC) is the modulation of oxidative phosphorylation in the mitochondria by competitive and reversible inhibition of cytochrome $\mathrm{c}$ oxidase, the terminal heme-containing enzyme in the mitochondrial respiratory chain. This suggests a crucial role of $\mathrm{NO}$ in regulation of energy generation. The action of NO is limited by its biologic half-life which is in vivo up to one second and by the relative short distance that this molecule can traverse.

The function of the nervous tissue is strictly dependent on aerobic metabolism. That is the reason why the regional $\mathrm{CBF}$ increases to balance oxygen demands during functional activation (so called neurovascular coupling or hemodynamic response) (Hoffmeyer et al. 2007, Lindauer et al. 1999b). The mechanism of the neurovascular coupling is region-specific and includes both astrocytic and neuronal compartments. Astrocytes are sensing the neuronal activity via receptors for many neurotransmitters which are located near the synapses. Their activation leads to the changes of astrocytic $\mathrm{Ca}^{2+}$ levels and to the production of arachidonic acid metabolites - prostaglandin $\mathrm{E}_{2}$ and epoxyeicosatrienoic acids which induce arteriole dilation (Haydon and Carmignoto 2006). In parallel to astrocytic regulatory system neurons expressing nNOS during the activation produce NO which directly diffuses to vascular smooth muscle cells (VSMCs) and dilates the arterioles. The vasorelaxant action of $\mathrm{NO}$ on the VSMCs involves the generation of cGMP and cGMP-dependent protein kinase
(PKG)-dependent modulation of ion channels, inducing hyperpolarization of the membrane. Moreover, NO activates sarcoplasmic-endoplasmic reticulum $\mathrm{Ca}^{2+}$ ATPases, depleting the $\mathrm{Ca}^{2+}$ levels of the cytosol (Guix et al. 2005).

NO is considered to play a role in the pathophysiology of epilepsy, although the results of experiments carried out by several authors are often discrepant. Available in vivo data show a lack of effect, a decrease or increase in seizure susceptibility following the administration of NOS inhibitors. The effects of NOS inhibitors are dependent on the type of inhibitor, the route of administration, the model of seizures and the species of animals used in experiments (Wojtal et al. 2003). Nevertheless, our recent findings suggest a crucial role of NO produced by nNOS in the initiation of epileptic seizures in vitro. The NOS inhibitor 7-nitroindazol (7-NI, putative nNOS inhibitor) in combination with potent $\mathrm{NO}$ scavenger (4-(carboxyphenyl)-4,4,5,5-tetramethylimidazole1-oxyl 3-oxide (c-PTIO)) was able to prevent the initiation of seizure-like events in low-magnesium model of seizures in acute hippocampal slice and organotypic hippocampal slice culture preparations (Kovacs et al. 2009).

One of the reasons why results from the acute in vivo studies display controversies might be the changes in the regulation of $\mathrm{CBF}$ during pharmacologically induced alterations of the NO system. However, the knowledge from this field is limited because of technical aspects. Anesthetics significantly influence blood pressure as well as cerebral hemodynamics. Furthermore, the recordings in freely moving animals are technically demanding and for that reason the results should be interpreted with caution due to frequent movement artefacts. In neurovascular coupling research $\alpha$-chloralose anesthesia is frequently used. However, due to its pharmacological properties and common occurrence of negative side effects (e.g. spreading depression) it is not suitable for epileptological studies. Therefore the current study was conducted to elucidate whether urethane anesthesia, which is frequently used to study epileptic events in anesthetized rats, is also convenient to study cerebrovascular dynamics.

\section{Methods}

\section{Animals}

Adult male Wistar rats (250-350 g, $\mathrm{n}=37)$ were used in our study. Rats were randomly divided into 
experimental groups (11 to monitor arterial blood pressure under urethane anesthesia, 10 to monitor blood pressure in conscious animals and 16 to monitor spontaneous brain activity, brain excitability and changes of $\mathrm{CBF}$ ). Rats were housed in standard plastic cages in temperature-controlled environment $\left(22 \pm 1^{\circ} \mathrm{C}\right)$, humidity $50-60 \%$ with a 12-h light/dark cycle (lights on at 6 am) with free access to food and water. All experiments were performed in agreement with the Animal Protection Law of the Czech Republic, and the project was approved by the Animal Care and Use Committee of the Institute of Physiology of the Academy of Sciences of the Czech Republic. All efforts were made to minimize animal suffering and to reduce the number of animals used.

\section{Drug treatment}

7-NI obtained from Sigma-Aldrich (Czech Republic), was dissolved in dimethyl sulfoxide (DMSO). All rats were given either 7-NI or its vehicle intraperitoneally in a volume of $1 \mathrm{ml} / \mathrm{kg}$ body weight. The dose of 7-NI $(25 \mathrm{mg} / \mathrm{kg})$ was selected on the basis of previous studies and because it is the most widely used dose in neuroprotection studies. Solutions were freshly prepared at the beginning of each experiment. Urethane was obtained from Sigma-Aldrich (Czech Republic) and dissolved to $20 \%$ in distilled water. Heparine (Zentiva, Czech Republic) was diluted to its final concentration $0.1 \%$ by sterile $0.01 \mathrm{M}$ phosphate buffered saline.

\section{Experimental procedures}

\section{Continuous recording of blood pressure and heart rate}

Under urethane anesthesia (1.2 g/kg i.p.) a chronic catheter was implanted into the common carotid artery in order to measure systemic arterial blood pressure. The carotid artery was carefully prepared from a small ventral midline neck incision. A vascular microclip was placed over both internal and common carotid artery. A ligation was placed on the common carotid artery as caudally as possible and the second ligation was prepared for the future fixation of the catheter near the bifurcation. After arteriotomy a plastic catheter (PE50) was inserted into the central portion of common carotid both ligations were tightened. To prevent thrombosis the catheter was filled up with $1 \%$ heparin solution. The catheter was then passed under the skin and the other ending was pulled out from a small nuchal incision and temporarily closed with a plug until connected to a recording tube (Zicha et al. 2008). This allowed us to measure BP in freely moving animals. Animals were placed into the stereotactic frame and their body temperature was maintained at $37.1 \pm 0.1^{\circ} \mathrm{C}$ by heating pad. The catheter was connected to the pressure sensor (BLPR2, WPI - Germany) and BP was continuously recorded with Spike2 software $(1 \mathrm{kHz})$. Heart rate was analyzed offline using power spectral algorithm in Spike2 software.

In order to assess the effect of urethane on cardiovascular dynamics same animals $(n=10)$ were implanted carotid catheter under isoflurane anesthesia (1.5-2\%) and then allowed to recover for $4 \mathrm{~h}$. After recovery animals were placed into the plastic box for the acute recordings of blood pressure and heart rate.

Measurements of brain activity, brain excitability and cerebral blood flow

Epidural recording electrodes were stereotactically implanted over both cerebral hemispheres (L $3.0 \mathrm{~mm}$, R-C $1.0 \mathrm{~mm}$; 2x L $3.0 \mathrm{~mm}$, R-C $3.0 \mathrm{~mm}$; L $4.0 \mathrm{~mm}$, R-C $5.5 \mathrm{~mm}$ ) under urethane anesthesia. Bipolar stimulation electrodes were placed over the right somatosensory cortex (L $2.5 \mathrm{~mm}$, R-C $1.0 \mathrm{~mm}$ anterior and $1.0 \mathrm{~mm}$ posterior in relation to bregma, $\mathrm{L}=2.5 \mathrm{~mm}$ ). A reference and a ground electrode were placed over the cerebellum. For the CBF measurements skull was thinned to improve laser light transmission. Therefore skull was carefully drilled contralaterally to the stimulating electrodes until internal cortical lamina was reached. The Laser Doppler probe was then placed directly on internal cortical lamina of the remaining bone and connected to the LDF (LDPM - PF5010, Perimed, Sweden) and digitalized at $256 \mathrm{~Hz}$. EEG data were acquired at $2 \mathrm{kHz}$ and bandpass filtered at 2 to $500 \mathrm{~Hz}$ (RA16PA preamplifier and Pentusa Base Station; Tucker-Davis Technologies, Gainesville, FL, U.S.A.).

To assess cerebrovascular reactivity electric stimulation of right sensorimotor cortex was performed by gradually increasing stimulations $(3,5,10$ and $15 \mathrm{~Hz}$, length $4 \mathrm{~s}$, intensity $3 \mathrm{~mA}$ ). Every stimulation was followed by a $3 \mathrm{~min}$ recovery period. The stimulation session was then repeated after $10 \mathrm{~min}$ and results were averaged for each frequency from both measurements. To assess the effect of 7-NI on spontaneous brain activity and brain excitability, the whole set of two stimulation sessions (see above) was repeated 30 min after treatment.

Data were analyzed offline using MATLAB software (Mathworks, Inc., Natick, MA, U.S.A.). For analysis of single evoked responses, the amplitude from the first negative wave (N1) to the following positive 
wave (P2) was measured. To evaluate the effect of treatment on the brain plasticity the sum of all evoked responses during one stimulation train was calculated ( $\sum$ of EP). The baselines of CBF were measured in $10 \mathrm{~s}$ window preceding the stimulation. The $\mathrm{CBF}$ responses to the stimulations were assessed by measuring peak amplitude.

\section{Statistical analysis}

The data were tested for normality and statistically evaluated using ANOVA for repeated measures (in the case of more than two groups) and t-test where appropriate (two groups). All data are expressed as mean \pm standard error of mean (S.E.M.).
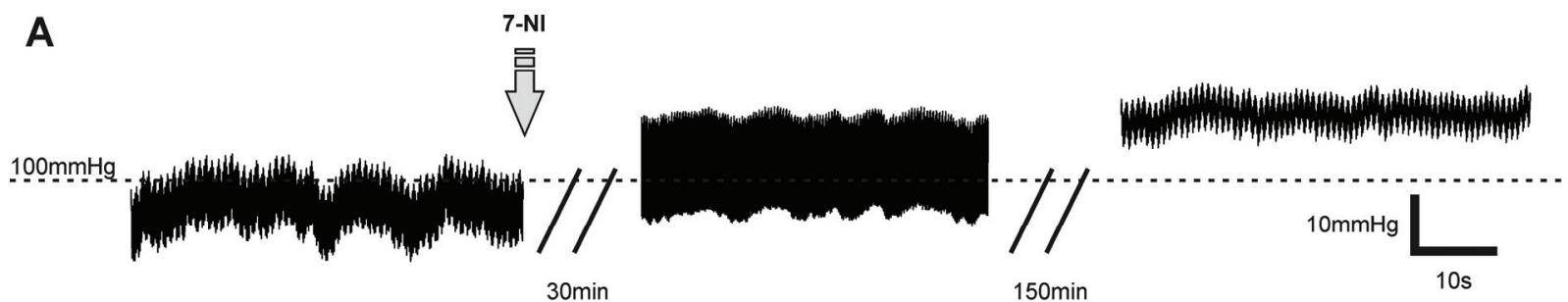

B

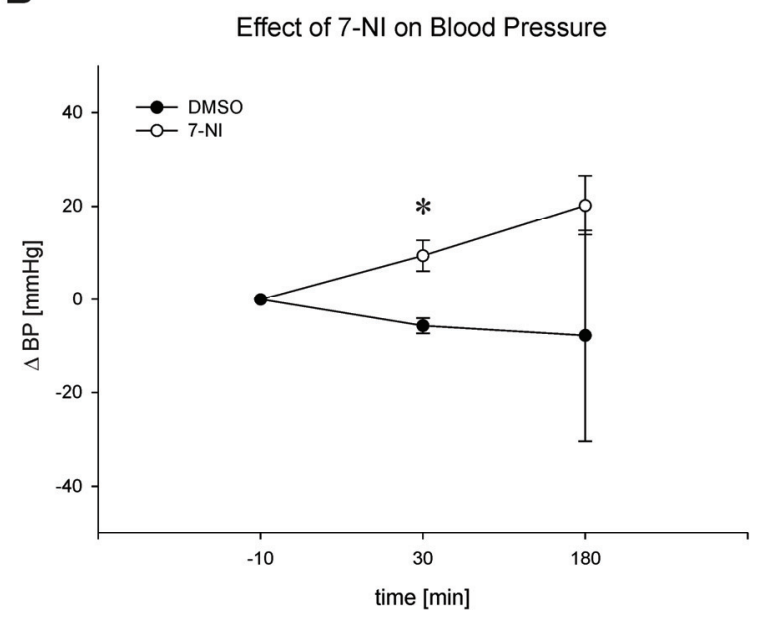

D

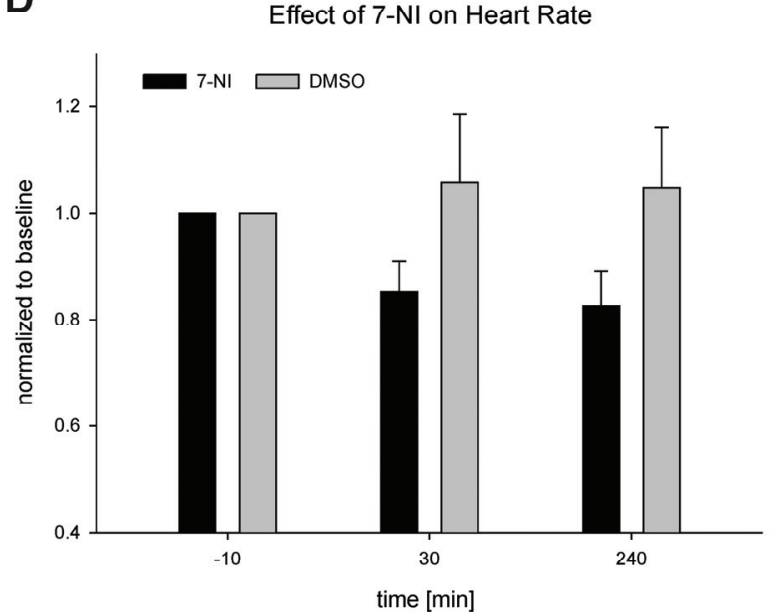

C

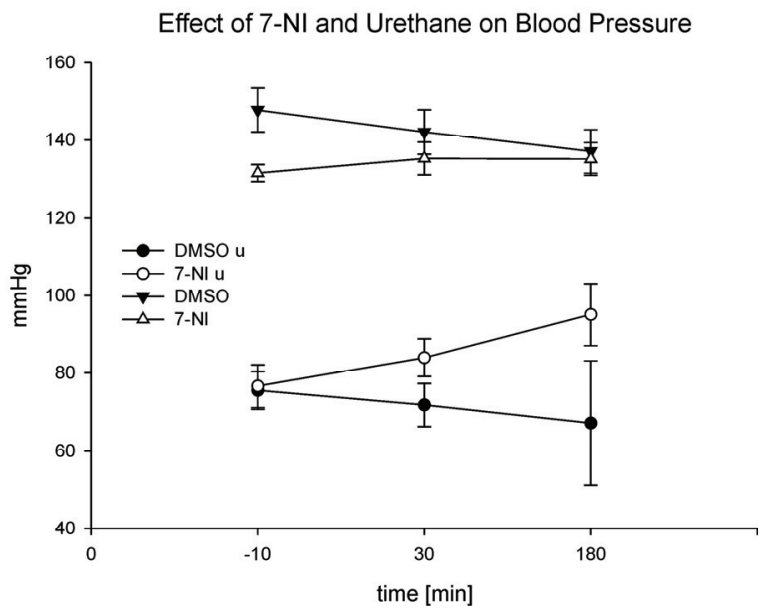

Fig. 1. Effect of 7-NI on physiological parameters - blood pressure and heart rate. (A) Blood pressure recording in a typical subject before and after 7-NI administration. (B, C) The systemic blood pressure in 7-NI treated rats was significantly higher 30 min after drug application in comparison to control animals: $83.95 \pm 4.84 \mathrm{mmHg}$ versus $71.79 \pm 5.50 \mathrm{mmHg}$ and at 30 and 180 minutes $(95.06 \pm 8.05 \mathrm{mmHg})$ after the 7-NI treatment when compared to initial values $(76.59 \pm 5.46 \mathrm{mmHg})$. Urethane significantly lowered baseline arterial blood pressure values in comparison with unanesthetized animals $(131.555 \pm 2.197 \mathrm{mmHg})$. (D) 7-NI did not induce significant changes in HR. Data shown in $\mathrm{D}$ have been normalized to the mean of their pretreatment magnitude. * shows statistically significant differences between 7-NI treated animals and control (DMSO) animals. 
A

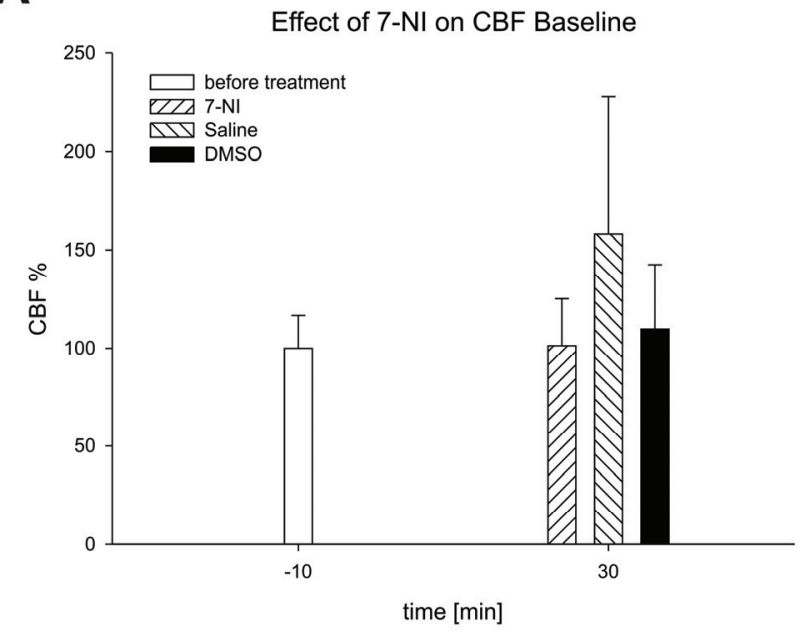

C

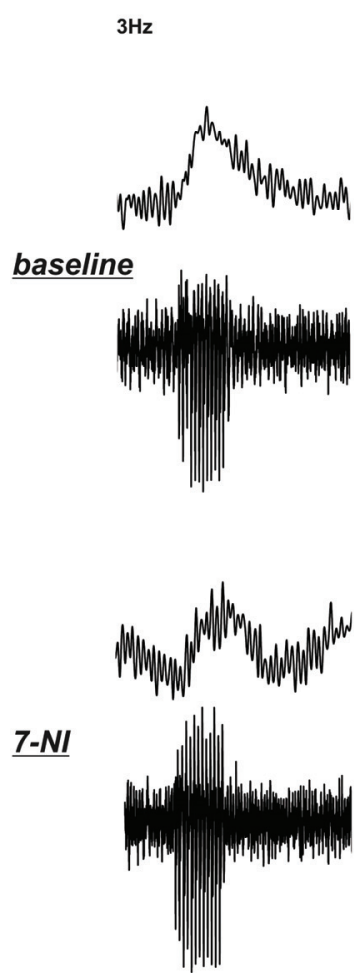

B

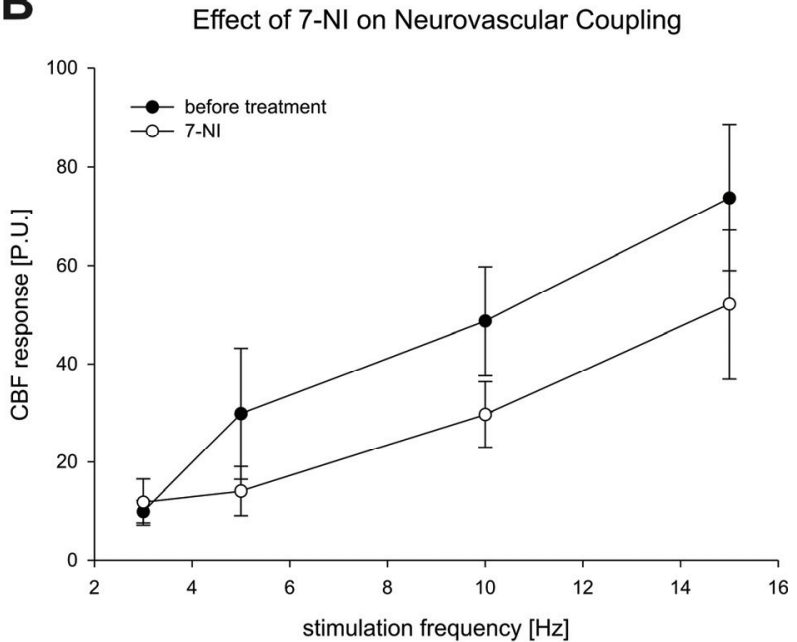

$5 \mathrm{~Hz}$

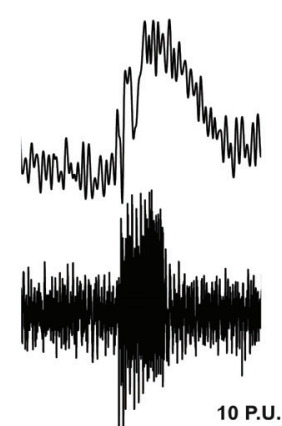

$10 \mathrm{~Hz}$

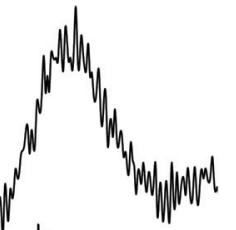
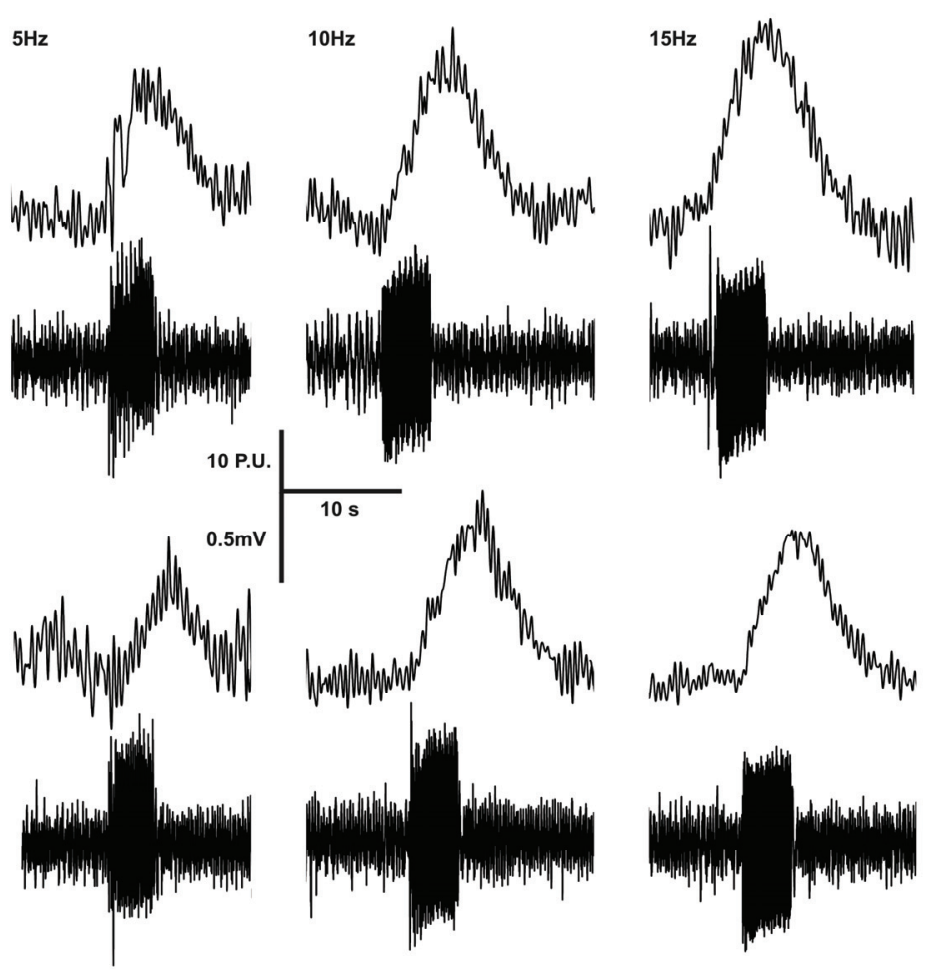

Fig. 2. Effect of 7-NI on cerebral hemodynamics. (A) Baseline regional cerebral blood flow did not change significantly during nNOS inhibition by 7-NI, neither did it change in control animals. (B) Average across subject hemodynamic responses plotted against the stimulation frequency. Transcallosal stimulation of the contralateral cortex induced a frequency dependent rise in rCBF which was nonsignificantly reduced during nNOS inhibition. (C) CBF measurings in a typical subject before and after the 7-NI treatment.

\section{Results}

\section{Effect of 7-NI on physiological parameters}

During the experimental period, mean values of arterial blood pressure significantly increased after 7-NI treatment under urethane anesthesia (Fig. 1B). The systemic blood pressure in 7-NI-treated rats was significantly higher $30 \mathrm{~min}$ after the drug injection in comparison to control animals (DMSO-treated): $83.95 \pm 4.84 \mathrm{mmHg}$ vs. $71.79 \pm 5.50 \mathrm{mmHg}$ (Fig. 1A).

Since our experiments were done under urethane anesthesia we measured the effect of urethane anesthesia on 7-NI-induced alterations of arterial blood pressure. Urethane significantly lowered arterial blood pressure 
(76.58 $\pm 5.46 \mathrm{mmHg})$ in comparison with conscious animals $(131.56 \pm 2.2 \mathrm{mmHg})$. However, 7-NI induced a nonsignificant increase in blood pressure $30 \mathrm{~min}$ after the treatment in conscious animals (Fig. 1C).

Heart rate was not changed either by the application of DMSO or by 7-NI. However, a slight decrease in HR was observed following 7-NI injection (Fig. 2).

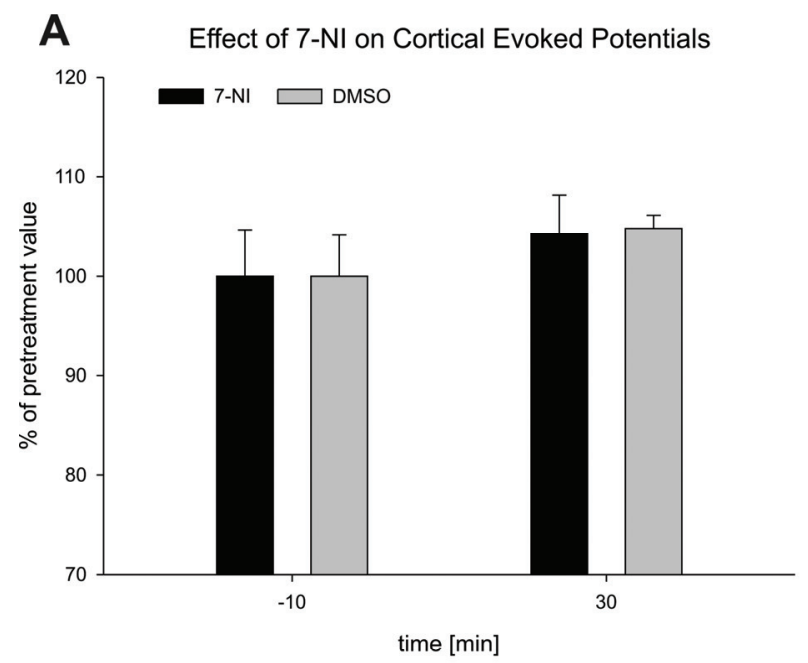

Effect of 7-NI on cerebral blood flow

We tested the effect of the inhibition of nNOS by 7-NI on resting CBF. Regional CBF did not significantly change during nNOS inhibition by 7-NI, neither did it change in control animals (DMSO-treated, Fig. 3).

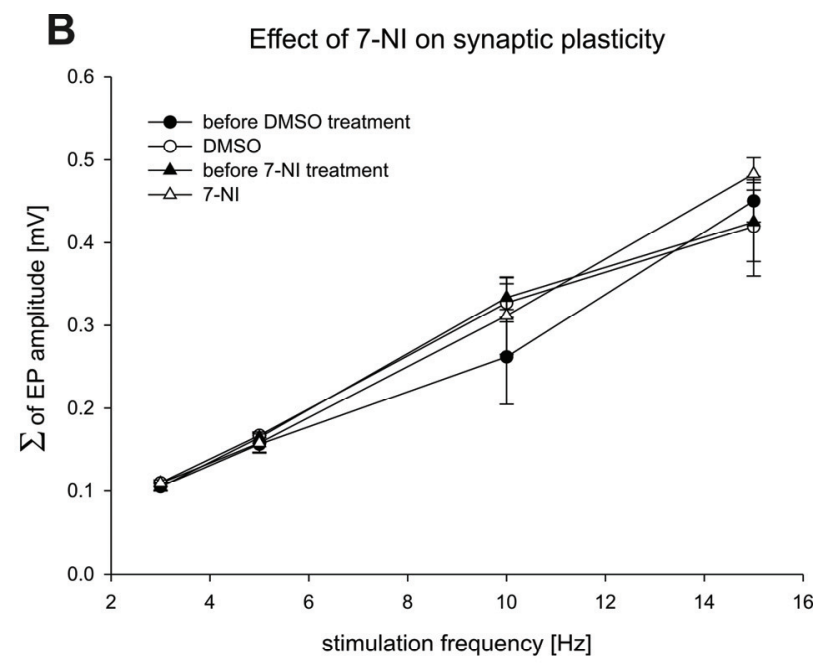

C

Control

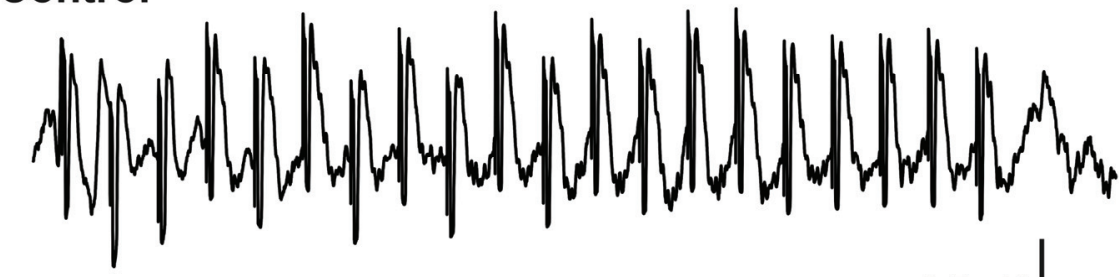

7-NI

$0.5 \mathrm{mV}$

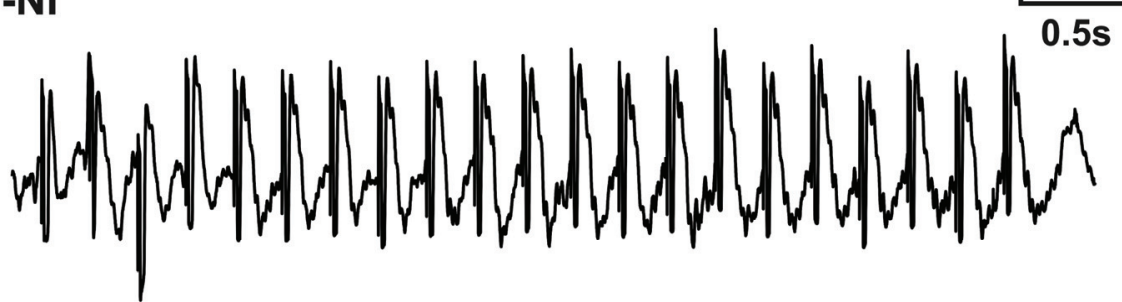

Fig. 3. Effect of 7-NI on cortical excitability. (A) The amplitude of cortical EPs in response to transcallosal stimulation did not change in both treatment groups 30 minutes after the application. (B) 7-NI did not induce changes of cortical EPs amplitude at any stimulation frequency. (C) A typical recording of cortical EPs at $5 \mathrm{~Hz}$ showing no changes in EP amplitude during stimulation trains.

\section{Effect of 7-NI on neuronal excitability}

To make sure that 7-NI does not cause changes in cortical excitability, cortical EPs were measured. Figure 3 shows the effect of 7-NI on EPs. There were no significant changes in the EPs evoked by transcallosal stimulation at any pharmacological situation, suggesting no effect of 7-NI on cortical neuronal excitability (Fig. 3A). Analysis of rhythmic stimulation did not reveal any effect of 7-NI on synaptic plasticity. The sum of the EPs during stimulation trains $(3,5,10$ and $15 \mathrm{~Hz})$ linearly increased with frequency (Fig. 3B). 


\section{Effect of 7-NI on neurovascular coupling}

Transcallosal stimulation of the contralateral cortex induces a frequency (dose) dependent rise in CBF. The application of 7-NI did not abolish the rise in CBF in response to the transcallosal stimulation. The amplitude of the hemodynamic responses increased with higher stimulation frequency in both groups. The dose response (the relation of $\mathrm{CBF}$ amplitude on stimulation frequency) demonstrates a linear relationship. However, we have observed a little decline of the dose-response curve after 7-NI treatment (Fig. 3).

\section{Discussion}

The results of the present study suggest that 7-NI has a significant effect on systemic blood pressure which was significantly increased both 30 and $180 \mathrm{~min}$ after 7NI treatment under urethane anesthesia. In conscious animals 7-NI induced an increase of blood pressure, however, this increase did not reach the level of statistical significance. Changes of blood pressure were accompanied by non-significant changes of heart rate. The wide range of effects of nNOS inhibition on systemic parameters reported in previous studies may result from differences in the measuring techniques, rat strain employed, the anesthesia, the inhibitor used, its relative degree of neuronal versus endothelial NOS inhibition achieved and solvent used (Cholet et al. 1997, Hoffmeyer et al. 2007, Lindauer et al. 1999b, Stefanovic et al. 2007, Toda et al. 2009, Togashi et al. 1992, Zagvazdin et al. 1996). Non-specific inhibitors of NOS have been shown to increase blood pressure (Rees et al. 1989). In contrast, 7-NI was proposed to be a specific nNOS inhibitor, because it had no effect on systemic blood pressure in anesthetized mice (Moore et al. 1993). However, this inhibitor induced a significant increase in blood pressure in our experiments. The role of $\mathrm{nNOS}$ in BP regulation is unclear.

The 7-NI injection slightly but non-significantly decreased basal CBF in our study. Other studies in conscious rats have reported that 7-NI decreased baseline CBF (Gotoh et al. 2001, Montecot et al. 1997) probably due to vasoconstriction of cerebral arterioles mediated by reduced production of NO by nNOS. However, in anesthetized rats 7-NI did not induce changes in resting CBF measured by autoradiography in the somatosensory cortex (Cholet et al. 1996). Furthermore, using functional magnetic resonance imaging Stefanovic et al. (2007) found that 7-NI had no effect on CBF in $\alpha$-chloralose anesthetized animals. Although 7-NI caused a slight decrease of the basal CBF values in our study, transcallosal stimulation of the sensorimotor cerebral cortex of one hemisphere caused a response in the homologous brain region on the opposite side which was observed as a corresponding rise in CBF. Rhythmic transcallosal stimulation is used to elicit a release of neurotransmitters especially glutamate which mimics enhanced brain activity. The regional CBF is likely controlled by a feed forward mechanism involving neuronal signaling via neurotransmitters mainly glutamate (Attwell and Iadecola 2002, Hoffmeyer et al. 2007). As mentioned earlier the mechanism of neurovascular coupling is region-specific and includes both astrocytic and neuronal compartments. In parallel to the astrocytic regulatory system, which is based on the release of arachidonic acid metabolites, the neurons expressing nNOS produce NO (activated by $\mathrm{Ca}^{2+}$ ) during the activation which directly diffuses to vascular smooth muscle cells and dilates the arterioles (Hoffmeyer et al. 2007).

In our experiment 7-NI had no influence on amplitudes of cortical evoked potentials. We have found no further effect of 7-NI on rhythmic potentiation or depression of the EPs. This finding is in accordance with previous experiments mainly done on somatosensory evoked potentials (Hoffmeyer et al. 2007, Lindauer et al. 1993, Lindauer et al. 1999). Furthermore, no concomitant changes in cerebral glucose metabolism during neuronal activity under the inhibition of nNOS were reported by Cholet et al. (1997). However, others observed a decrease in somatosensory-evoked potential amplitudes after nNOS inhibition (Ngai et al. 1995, Stefanovic et al. 2007) in $\alpha$-chloralose anesthetized rats. Variability of these findings might be explained by different placement of cortical electrodes for EP recording (Ngai et al. 1998) and the involvement of polysynaptic path in somatosensory EPs in contrast to monosynaptic transcallosal path.

Although 7-NI did not significantly affect basal $\mathrm{CBF}$ and cortical excitability, hemodynamic responses to the transcallosal stimulation were diminished implicating a role of nNOS in neurovascular coupling. In the present study, we have observed a significant increase of CBF during gradual frequency-increasing stimulation even after the injected dose of 7-NI $(25 \mathrm{mg} / \mathrm{kg})$. However, the dose-response (dependency of amplitude of the CBF response on stimulation frequency) indicates a little decline from control measurements confirming a role of 
nNOS in hemodynamic response to transcallosal stimulation. Similar results have been shown also by others using different anesthesia and stimulation protocols (Hoffmeyer et al. 2007, Lindauer et al. 1999).

The research of neurovascular coupling in vivo is commonly performed on $\alpha$-chloralose anesthetized animals because it appears to have little effect on cardiovascular reflexes, peripheral resistance and cerebral vasoreactivity (Lindauer et al. 1993, Maggi and Meli 1986, Smith and Hutchins 1980). Early studies have shown that $\alpha$-chloralose preserves robust and stable hemodynamic and metabolic coupling to sensory stimulation (Lindauer et al. 1993). However, $\alpha$-chloralose has a broad effect on systemic parameters; it induces respiratory depression, metabolic acidosis, and bronchial hyperreactivity (Arfors et al. 1971). The action of $\alpha$ chloralose has been shown to involve the potentiation of $\mathrm{GABA}_{\mathrm{A}}$-induced currents by increasing the affinity for GABA (Garrett and Gan 1998), whereas at low concentration $\alpha$-chloralose does not affect glutamatergic, glycinergic or cholinergic synaptic transmission (Wang et al. 2008). Animals with $\alpha$-chloralose anesthesia show increased brain excitability and the rhythmic stimulation of the cortex frequently induces spreading depression. For that reason a topically administrated cocktail of ionotropic glutamate receptor blockers is commonly used in neurovascular coupling research (Hoffmeyer et al. 2007, Lindauer et al. 1999). Austin et al. (2005) showed that in rats under $\alpha$-chloralose (10 to $30 \mathrm{mg} / \mathrm{kg}$ per hour) sensory stimulation induced varying electroencephalographic and BOLD responses over a longer period of measurements. Altogether, the above mentioned findings demonstrate that $\alpha$-chloralose is not a suitable anesthesia for electrophysiological animal experiments in epileptology. Contrarily, urethane has been often used in neurophysiologic studies e.g. to describe firing properties of hippocampal neurons, electrically induced hippocampal gamma oscillations and epileptic activity (Garcia-Hernandez et al. 2010, Mikkonen et al. 2002, Stringer and Sowell 1994). Urethane has only modest effects on multiple neurotransmitter-gated ion channels at concentrations close to the anesthetic half maximal effective concentration $\left(\mathrm{EC}_{50}\right)$ and thus urethane is suitable for maintaining anesthesia during electrophysiologic recordings (Hara and Harris 2002). Our results indicate that urethane besides its hypotensive effect has minimal if any influence on hemodynamic responses.

In conclusion, our data suggest that urethane is a suitable anesthetic for further research of neurovascular coupling during epileptic events. Inhibition of neuronal nitric oxide synthase by 7-NI influenced hemodynamic responses but did not affect blood pressure, heart rate or brain excitability in urethane anesthetized rats.

\section{Conflict of Interest}

There is no conflict of interest.

\section{Acknowledgements}

This study was supported by Grants number P303/10/0999, P304/11/P386 and P304/12/G069 from Czech Science Foundation and project AV0Z50110509.

\section{References}

ARFORS KE, ARTURSON G, MALMBERG P: Effect of prolonged chloralose anesthesia on acid-base balance and cardiovascular functions in dogs. Acta Physiol Scand 81: 47-53, 1971.

ATTWELL D, IADECOLA C: The neural basis of functional brain imaging signals. Trends Neurosci 25: 621-625, 2002.

AUSTIN VC, BLAMIRE AM, ALLERS KA, SHARP T, STYLES P, MATTHEWS PM, SIBSON NR: Confounding effects of anesthesia on functional activation in rodent brain: a study of halothane and alpha-chloralose anesthesia. Neuroimage 24: 92-100, 2005.

BAL-PRICE A, BROWN GC: Inflammatory neurodegeneration mediated by nitric oxide from activated glia-inhibiting neuronal respiration, causing glutamate release and excitotoxicity. $J$ Neurosci 21: 6480-6491, 2001.

BON CL, GARTHWAITE J: On the role of nitric oxide in hippocampal long-term potentiation. J Neurosci 23: 1941 1948, 2003.

BROWN GC: Regulation of mitochondrial respiration by nitric oxide inhibition of cytochrome c oxidase. Biochim Biophys Acta 1504: 46-57, 2001.

BUCHHOLZER ML, KLEIN J: NMDA-induced acetylcholine release in mouse striatum: role of NO synthase isoforms. J Neurochem 82: 1558-1560, 2002. 
CHOLET N, BONVENTO G, SEYLAZ J: Effect of neuronal NO synthase inhibition on the cerebral vasodilatory response to somatosensory stimulation. Brain Res 708: 197-200, 1996.

CHOLET N, SEYLAZ J, LACOMBE P, BONVENTO G: Local uncoupling of the cerebrovascular and metabolic responses to somatosensory stimulation after neuronal nitric oxide synthase inhibition. J Cereb Blood Flow Metab 17: 1191-1201, 1997.

GARCIA-HERNANDEZ A, BLAND BH, FACELLI JC, COLOM L: Septo-hippocampal networks in chronic epilepsy. Exp Neurol 222: 86-92, 2010.

GARRETT KM, GAN J: Enhancement of gamma-aminobutyric acidA receptor activity by alpha-chloralose. J Pharmacol Exp Ther 285: 680-686,1998.

GARTHWAITE J, CHARLES SL, CHESS-WILLIAMS R: Endothelium-derived relaxing factor release on activation of NMDA receptors suggests role as intercellular messenger in the brain. Nature 336: 385-388, 1988.

GOTOH J, KUANG TY, NAKAO Y, COHEN DM, MELZER P, ITOH Y, PAK H, PETTIGREW K, SOKOLOFF L: Regional differences in mechanisms of cerebral circulatory response to neuronal activation. Am J Physiol 280: H821-H829, 2001.

GUIX FX, URIBESALGO I, COMA M, MUNOZ FJ: The physiology and pathophysiology of nitric oxide in the brain. Prog Neurobiol 76: 126-152, 2005.

HARA K, HARRIS RA: The anesthetic mechanism of urethane: the effects on neurotransmitter-gated ion channels. Anesth Analg 94: 313-318, table, 2002.

HAYDON PG, CARMIGNOTO G: Astrocyte control of synaptic transmission and neurovascular coupling. Physiol Rev 86: 1009-1031, 2006.

HOFFMEYER HW, ENAGER P, THOMSEN KJ, LAURITZEN MJ: Nonlinear neurovascular coupling in rat sensory cortex by activation of transcallosal fibers. J Cereb Blood Flow Metab 27: 575-587, 2007.

KOVACS R, RABANUS A, OTAHAL J, PATZAK A, KARDOS J, ALBUS K, HEINEMANN U, KANN O: Endogenous nitric oxide is a key promoting factor for initiation of seizure-like events in hippocampal and entorhinal cortex slices. J Neurosci 29: 8565-8577, 2009.

KURIHARA N, ALFIE ME, SIGMON DH, RHALEB NE, SHESELY EG, CARRETERO OA: Role of nNOS in blood pressure regulation in eNOS null mutant mice. Hypertension 32: 856-861, 1998.

LINDAUER U, VILLRINGER A, DIRNAGL U: Characterization of CBF response to somatosensory stimulation: model and influence of anesthetics. Am J Physiol 264: H1223-H1228, 1993.

LINDAUER U, MEGOW D, MATSUDA H, DIRNAGL U: Nitric oxide: a modulator, but not a mediator, of neurovascular coupling in rat somatosensory cortex. Am J Physiol 277: H799-H811, 1999.

MAGGI CA, MELI A: Suitability of urethane anesthesia for physiopharmacological investigations in various systems. Part 2: Cardiovascular system. Experientia 42: 292-297, 1986.

MIKKONEN JE, GRONFORS T, CHROBAK JJ, PENTTONEN M: Hippocampus retains the periodicity of gamma stimulation in vivo. $J$ Neurophysiol 88: 2349-2354, 2002.

MONTECOT C, BORREDON J, SEYLAZ J, PINARD E: Nitric oxide of neuronal origin is involved in cerebral blood flow increase during seizures induced by kainate. J Cereb Blood Flow Metab 17: 94-99, 1997.

MOORE PK, BABBEDGE RC, WALLACE P, GAFFEN ZA, HART SL: 7-Nitro indazole, an inhibitor of nitric oxide synthase, exhibits anti-nociceptive activity in the mouse without increasing blood pressure. Br J Pharmacol 108: 296-297, 1993.

NGAI AC, MENO JR, JOLLEY MA, WINN HR: Suppression of somatosensory evoked potentials by nitric oxide synthase inhibition in rats: methodological differences. Neurosci Lett 245: 171-174, 1998.

NGAI WM, REILLY RM, POLIHRONIS J, SHPITZ B: In vitro and in vivo evaluation of streptavidin immunoconjugates of the second generation TAG-72 monoclonal antibody CC49. Nucl Med Biol 22: 77-86, 1995.

PRAST H, TRAN MH, FISCHER H, PHILIPPU A: Nitric oxide-induced release of acetylcholine in the nucleus accumbens: role of cyclic GMP, glutamate, and GABA. J Neurochem 71: 266-273, 1998.

REES DD, PALMER RM, MONCADA S: Role of endothelium-derived nitric oxide in the regulation of blood pressure. Proc Natl Acad Sci U S A 86: 3375-3378, 1989. 
SARANSAARI P, OJA SS: Involvement of nitric oxide in adenosine release in the developing and adult mouse hippocampus. Neurochem Res 29: 219-225, 2004.

SMITH TL, HUTCHINS PM: Anesthetic effects on hemodynamics of spontaneously hypertensive and Wistar-Kyoto rats. Am J Physiol 238: H539-H544, 1980.

STEFANOVIC B, SCHWINDT W, HOEHN M, SILVA AC: Functional uncoupling of hemodynamic from neuronal response by inhibition of neuronal nitric oxide synthase. J Cereb Blood Flow Metab 27: 741-754, 2007.

STRINGER JL, SOWELL KL: Kainic acid, bicuculline, pentylenetetrazol and pilocarpine elicit maximal dentate activation in the anesthetized rat. Epilepsy Res 18: 11-21, 1994.

TODA N, AYAJIKI K, OKAMURA T: Cerebral blood flow regulation by nitric oxide: recent advances. Pharmacol Rev 61: 62-97, 2009.

TOGASHI H, SAKUMA I, YOSHIOKA M, KOBAYASHI T, YASUDA H, KITABATAKE A, SAITO H, GROSS SS, LEVI R: A central nervous system action of nitric oxide in blood pressure regulation. J Pharmacol Exp Ther 262: 343-347, 1992.

TRABACE L, CASSANO T, TUCCI P, STEARDO L, KENDRICK KM, CUOMO V: The effects of nitric oxide on striatal serotoninergic transmission involve multiple targets: an in vivo microdialysis study in the awake rat. Brain Res 1008: 293-298, 2004.

WALL MJ: Endogenous nitric oxide modulates GABAergic transmission to granule cells in adult rat cerebellum. Eur $J$ Neurosci 18: 869-878, 2003.

WANG K, ZHENG C, WU C, GAO M, LIU Q, YANG K, ELLSWORTH K, XU L, WU J: alpha-Chloralose diminishes gamma oscillations in rat hippocampal slices. Neurosci Lett 441: 66-71, 2008.

WOJTAL K, GNIATKOWSKA-NOWAKOWSKA A, CZUCZWAR SJ: Is nitric oxide involved in the anticonvulsant action of antiepileptic drugs? Pol J Pharmacol 55: 535-542, 2003.

ZAGVAZDIN Y, SANCESARIO G, WANG YX, SHARE L, FITZGERALD ME, REINER A: Evidence from its cardiovascular effects that 7-nitroindazole may inhibit endothelial nitric oxide synthase in vivo. Eur $J$ Pharmacol 303: 61-69, 1996.

ZICHA J, DOBESOVA Z, KUNES J: Late blood pressure reduction in SHR subjected to transient captopril treatment in youth: possible mechanisms. Physiol Res 57: 495-498, 2008. 